\title{
EFEITO DO BIOATIVADOR DE SOLO NO DESENVOLVIMENTO INICIAL DO CAFEEIRO
}

Eduardo Martins de Souza ${ }^{1}$, Kleso Silva Franco Júnior ${ }^{2 *}$, Giselle Prado Brigante ${ }^{3}$, Carlos Eduardo Brockelmann ${ }^{4}$, Renata Mendes Tavares ${ }^{5}$, Márcio de Souza Dias ${ }^{6}$, Douglas José Marques ${ }^{7}$, João Paulo Costa Carneiro ${ }^{8}$

RESUMO - A cafeicultura tem grande importância econômica no território nacional, entretanto, enfrenta algumas limitações no seu manejo, principalmente na sua implantação, pelo fato de comprometer todo o processo produtivo. A utilização de bioativadores de microrganismos no solo na instalação de lavouras cafeeiras gera um impacto de reciclagem de nutrientes auxiliando no aproveitamento, desenvolvimento e absorção da lavoura cafeeira. Os bioestimulantes à base de algas marinhas, enzimas e microrganismos do solo, vêm sendo utilizados como uma alternativa para nutrição de plantas, pelo fato da intensa demanda de nutrientes no sistema atual de agricultura. Neste estudo, objetivou-se verificar o efeito de diferentes dosagens de bioativador de solo (Vitasoil ${ }^{\circledR}$ ) na implantação de lavoura cafeeira arábica (Catuai Vermelho IAC 144). Foram testados uma aplicação via solo em 5 doses, 4, 6, 8,10 e 12 gramas hectare $^{-1}$, acrescidas de 3 aplicações via foliares de 3 gramas de Vitasoil. Para fazer a utilização do mesmo, ocorreu a hidratação com $100 \mathrm{~mL}$ de água para cada grama de produto. As avaliações foram realizadas aos 120 dias, onde foi avaliado: as medições da parte aérea e radicular, contagem de folhas, espessura do caule, pesagem da fração aérea e radicular verde e seca, área foliar e relação parte aérea /raiz. O delineamento experimental foi em blocos ao acaso. Entre os dados analisados observou que o uso do bioativador se mostrou superior estatisticamente quando comparado à testemunha, não diferindo entre si em dosagens. O ativador de microbiota de solo (Vitasoil ${ }^{\mathbb{Q}}$ ) aplicado via solo e foliar em mudas de café, promoveu um melhor desenvolvimento inicial do cafeeiro sendo observado em diâmetro, peso verde e seco, número de folhas por muda, área foliar, altura de planta, comprimento de raiz e relação parte aérea/raiz.

Palavras chave: bioestimulantes, Coffea arabica, instalação, microorganismos.

\section{EFFECT OF SOIL BIOACTIVATOR IN COFFEE INITIAL DEVELOPMENT}

\begin{abstract}
Coffee growing has great economic importance in the national territory, however, faces some limitations in its management, especially in its implementation, because it compromises the entire production process. The use of microorganism bioactivators in the soil in the coffee plantation installation generates a nutrient recycling impact helping in the utilization, development and absorption of the coffee crop. Seaweedbased biostimulants, enzymes and soil microorganisms have been used as an alternative for plant nutrition due to the intense nutrient demand in the current agriculture system. This study aimed to verify the effect of different dosages of soil bioactivator (Vitasoil ${ }^{\mathbb{}}$ ) on the implantation of arabica coffee crop (Catuai Vermelho IAC 144). Soil application was tested in 5 doses, 4, 6, 8, 10 and 12 grams hectare $^{-1}$, plus 3 applications by leaf of 3 grams of Vitasoil $^{\mathbb{}}$. To make use of it, hydration with $100 \mathrm{~mL}$ of water for each gram of product occurred. The evaluations were performed at 120 days, where it was evaluated: the shoot and root measurements, leaf count, stem thickness, green and dry root and weight fraction, leaf area and shoot / root ratio. The experimental design was randomized blocks. Among the analyzed data, it was observed that the use of the bioactivator was statistically superior when

\footnotetext{
1,4 Eng.-Agrônomo CESEP - Centro Universitário - E-mail: eduardosouza.mp@hotmail.com; kadubrockelmann@gmail.com.

2.3 Eng.-Agrônomo Prof. DSc. E-mail: kleso.junior@yahoo.com.br (ORCID:0000-0002-6807-8889); giselle.brigante@gmail.com

4 Profa. CESEP- E-mail: retavares@yahoo.com.br.

6,7 UNIFENAS - E-mail: marciodesouzadias2013@gmail.com (ORCID: 0000-0001-8367-1341); douglas.marques@unifenas.br.

VESICA - E-mail: joao.carneiro@vesicacorp.com.
} 
compared to the control, not differing in dosages. Soil microbiota activator (Vitasoil ${ }^{\circledR}$ ) applied via soil and leaf in coffee seedlings, promoted a better initial development of the coffee tree being observed in diameter, green and dry weight, number of leaves per seedling, leaf area, plant height. root length and shoot / root ratio.

Keywords: biostimulants, Coffea arabica, installation, microorganisms.

\section{INTRODUÇÃO}

Os sistemas agrícolas atuais necessitam do uso de novas tecnologias para poder suprir a demanda crescente de alimentos pelo mundo. $\mathrm{O}$ uso desordenado de insumos e defensivos agrícolas tem causado desequilíbrios químicos, físicos e biológicos do solo, o que reduz de forma acentuada a diversidade microbiana a qual é fundamental para a eficiência do solo e dos cultivos. O Coffea arabica, é uma planta com porte arbustivo, pertencente à família rubiácea e gênero Coffea, com caule lenhoso, lignificado, reto e quase cilíndrico (Dias, 2007). No manejo nutricional do cafeeiro adulto e na fase de formação deve se levar em consideração o seu estado vegetativo, potencial de produção e carga pendente, além das características de solo e os adubos a serem utilizados (Matiello et al., 2002).

Os processos de decomposição e mineralização o destino inicial do Carbono (C) proveniente dos resíduos orgânicos é o $\mathrm{C}$ da biomassa microbiana, o qual pode passar posteriormente para formas mais estáveis de $\mathrm{C}$ no solo, sendo a maior parte perdida para a atmosfera como $\mathrm{CO}_{2}$ (Cardoso et al., 2011). O C associado à biomassa microbiana representa um dos compartimentos da matéria orgânica (MO) com menor tempo de ciclagem, 2,5 anos em condições de clima temperado e 3 meses em condições de clima tropical úmido (Silva et al., 2010), com tendência da biomassa microbiana ser maior em camadas mais superficiais pela maior disponibilidade de matéria orgânica, água e outros nutrientes.

Estudos relacionados ao fracionamento físico do solo indicam a predominância da atividade de várias enzimas como catalase, desidrogenase, urease e protease nas microunidades estruturais com diâmetros menores que $50 \mu \mathrm{m}$, indicando que a atividade enzimática apresenta forte relação com o estado de agregação do solo. Por esta razão e também por serem muito sensíveis a mudanças no solo (Dick et al., 1994), as enzimas são consideradas bons indicadores de qualidade do solo (Tótola \& Chaer, 2002).

Nos últimos anos, tem sido observado crescente interesse em substâncias bioestimulantes naturais para uso na agricultura, entretanto, a utilização das algas marinhas no mercado agrícola ainda é pouco representativa, apesar das pesquisas científicas mostrarem a sua grande potencialidade (Matysiak et al., 2011).
Atualmente, as algas são utilizadas nas formas secas ou extratos, comercializadas em nível mundial como bioestimulantes e/ou fertilizantes. O vasto grupo de macroalgas representa fonte de diversas substâncias valiosas a partir do ponto de vista fisiológico, que particularmente auxiliam as plantas a se adaptarem às condições de estresse (Matysiak et al., 2011).

Os extratos de algas marinhas contêm diversos reguladores de crescimento, tais como citocininas, auxinas, giberelinas (Durand et al., 2003), além de alguns macronutrientes, como $\mathrm{Ca}, \mathrm{K}$, P, e micronutrientes como Fe, Cu, Zn, B, Mn, Co, Mo (Khan et al., 2009), necessários para o desenvolvimento e crescimento de plantas. A utilização de extratos de algas vem ganhando popularidade, em razão do seu potencial de uso na agricultura orgânica e sustentável (Aziz et al., 2003) como alternativa para evitar a utilização excessiva de fertilizantes e para melhorar a absorção de minerais. Ao contrário dos fertilizantes químicos, os extratos de algas são biodegradáveis, não tóxicos, não poluentes e não perigosos para os seres humanos e animais (Rathore, 2009). As macroalgas marinhas sintetizam hormônios vegetais, além disso, existem relatos de respostas das algas sobre o crescimento de plantas, resistência aos estresses bióticos e abióticos, qualidade nutricional dos alimentos e favorecimento de microrganismos benéficos do solo (Khan et al., 2009).

Neste sentido objetivou-se avaliar o desenvolvimento inicial da lavoura cafeeira arábica, utilizando ativador de microbiota do solo $\left(\right.$ Vitasoil $\left.^{\circledR}\right)$, visando melhoria biológica do solo para a qual consequentemente irá proporcionar melhor desenvolvimento da planta.

\section{MATERIAL E MÉTODOS}

A pesquisa foi realizada no Sítio Nossa Senhora Aparecida, situado no município de Cordislândia - MG, Sul do Estado de Minas Gerais, com coordenadas geográficas $21^{\circ} 47^{\prime} 33^{\prime \prime}$ de latitude S e $45^{\circ} 42^{\prime} 03^{\prime}$ 'de longitude W, altitude média de $819 \mathrm{~m}$, temperatura média anual de $20,3^{\circ} \mathrm{C}$ e precipitação média anual de $1.414 \mathrm{~mm}$, dados esses que foram obtidos com base em Souza \& Souza (2017).

O solo utilizado foi classificado como Oxisol, com textura argilosa, com teores de nutrientes apresentados na Tabela 1. 
Tabela 1 - Análise química do solo utilizado na pesquisa

\begin{tabular}{|c|c|c|c|c|c|c|c|c|c|c|c|c|}
\hline $\mathrm{pH}$ & $\mathrm{P}$ & $\mathrm{K}$ & $\mathrm{Ca}^{2+}$ & $\mathrm{Mg}^{2+}$ & $\mathrm{Al}^{3+}$ & $\mathrm{H}+\mathrm{Al}$ & SB & $\mathrm{t}$ & $\mathrm{T}$ & V & $\mathrm{m}$ & MO \\
\hline $\mathrm{CaCl}_{2}$ & \multicolumn{2}{|c|}{$--\mathrm{mg} / \mathrm{dm}^{-3}--$} & \multicolumn{7}{|c|}{ - } & $\%$ & $\%$ & dag/ $\mathrm{Kg}^{-1}$ \\
\hline 4,85 & 8,3 & 122 & 2,93 & 0,93 & 1,9 & 5,8 & 4,17 & 6,1 & 9,97 & 41,8 & 31,6 & 2,9 \\
\hline
\end{tabular}

Realizou-se a calagem conforme recomendação baseada na análise de solo e de acordo com Guimarães et al. (1999).

Foram utilizados 54 sacos plásticos com volume de 20 litros cada, compostos com substrato contendo 700 litros de terra peneirada, 400 litros de esterco bovino curtido, acrescentado $5 \mathrm{~kg}$ de superfosfato simples (18\% $\left.\mathrm{P}_{2} \mathrm{O}_{5}\right)$ e $1 \mathrm{~kg}$ de cloreto de potássio $\left(58 \%\right.$ de $\left.\mathrm{K}_{2} \mathrm{O}\right)$. As mudas de café (Catuaí vermelho IAC 144) com 240 dias de idade produzidas na safra 2017/2018, foram submetidas ao transplante para sacos plásticos no dia 16 de junho de 2018, em seguida acondicionadas ao pleno sol, sendo feita a irrigação manual a cada dois dias por meio da utilização de copos dosador com um volume de $500 \mathrm{~mL}$ por planta.

Após o transplante das mudas foi realizado a aplicação do ativador de microbiota de solo $\left(\right.$ Vitasoil $\left.^{\circledR}\right)$. Para a aplicação o Vitasoil ${ }^{\circledR}$ foi diluído em água não clorada na proporção de $1 \mathrm{~g}$ para $100 \mathrm{~mL}$ de água, após a hidratação e homogeneização, aguardou $48 \mathrm{~h}$ para utilização. $\mathrm{Na}$ aplicação via solo utilizou doses em cinco níveis, 4, 6, 8, 10 e 12 gramas por hectare, somadas a 3 aplicações líquidas via foliar na dosagem de 3 gramas por hectare após 10 , 40 e 70 dias da implantação tendo como testemunha nove plantas que não receberam aplicação do Vitasoil $^{\circledR}$, assim totalizando 54 parcelas experimentais.

As plantas foram coletadas em 16 de outubro de 2018 e submetidas às avaliações de medições da parte aérea e radicular, com o auxílio de uma trena métrica, contagem manual de folhas, na espessura do caule se utilizou de paquímetro para coletas dos dados, no processo de pesagem da fração aérea e radicular, utilizou balança de precisão e após secagem em estufa de circulação força de ar à 60 ${ }^{\circ} \mathbf{C}$, pesou a parte aérea e radicular com auxílio da mesma, posteriormente sendo efetuado o cálculo do índice de área foliar (IAF), tendo como fórmula: : Comprimento (C) $\mathrm{x}$ Largura (L) x 0,6693, obtendo resultados em $\mathrm{cm}^{2}$ (Barros et al.,1973). Na obtenção dos resultados da relação parte aérea /raiz, dividiu a massa seca da parte aérea pela massa seca do sistema radicular (Barros et al., 1973).

O delineamento experimental foi em blocos ao acaso e os dados foram analisados por meio de análise de variância no teste de Scott-Knott a 5\% de significância, por meio de software estatístico SISVAR ${ }^{\circledR}$ (Ferreira, 2014).

\section{RESULTADOS E DISCUSSÃO}

Independente dos tratamentos (dosagens) utilizados de ativador de microbiota do solo $\left(\right.$ Vitasoil $^{\circledR}$ ) apresentou-se valores maiores significativamente que a testemunha, para parâmetros como diâmetro do caule, número de folhas por muda e área foliar (Tabela 2), sendo um resultado semelhante obtido por Schneiders (2016), quando testou a influência do extrato de alga (Ascophyllum nodosum) sobre o desempenho da cultura da canola, obtendo como resultado um aumento significativo no diâmetro de caule, já por Limberger (2012), quando avaliou o efeito da aplicação foliar de extrato de algas, aminoácidos e nutrientes via foliar na produtividade e qualidade de alface crespa, obteve um resultado positivo para número de folhas produzidas e área foliar.

Tabela 2 - Diâmetro do caule, número de folhas por muda e área foliar da cultivar Catuai 144 vermelho

\begin{tabular}{lccc}
\hline Tratamento & $\begin{array}{c}\text { Diâmetro do caule } \\
\mathrm{mm}\end{array}$ & N. ${ }^{o}$ folhas/mudas & $\begin{array}{c}\text { Area foliar** } \\
\mathrm{cm}^{2}\end{array}$ \\
\hline Testemunha & $4,833333 \mathrm{~B}$ & $13,666667 \mathrm{~B}$ & $270,758889 \mathrm{~B}$ \\
Dose $4 \mathrm{~g} / \mathrm{ha}$ & $7,000000 \mathrm{~A}$ & $39,222222 \mathrm{~A}$ & $1246,942222 \mathrm{~A}$ \\
Dose $6 \mathrm{~g} / \mathrm{ha}$ & $6,777778 \mathrm{~A}$ & $40,333333 \mathrm{~A}$ & $1282,266667 \mathrm{~A}$ \\
Dose $8 \mathrm{~g} / \mathrm{ha}$ & $6,888889 \mathrm{~A}$ & $38,555556 \mathrm{~A}$ & $1225,747778 \mathrm{~A}$ \\
Dose $10 \mathrm{~g} / \mathrm{ha}$ & $6,666667 \mathrm{~A}$ & $47,666667 \mathrm{~A}$ & $1515,184444 \mathrm{~A}$ \\
Dose $12 \mathrm{~g} / \mathrm{ha}$ & $7,333333 \mathrm{~A}$ & $41,777778 \mathrm{~A}$ & $1328,187778 \mathrm{~A}$ \\
\hline
\end{tabular}

*As médias seguidas por letras diferentes umas das outras pelo teste de Scott-Knott a 5\% de probabilidade. ${ }^{* *}$ (IAF $=\mathrm{C} \times \mathrm{L}$ x 0,6693$)$. 
Quanto à altura da planta, comprimento da raiz e relação parte aérea e raiz observou resultados superiores quando comparados à testemunha, cujos resultados obtidos por Araújo (2017) forma semelhantes aos apresentados, quando utilizou extrato de algas marinhas como bioestimulantes no crescimento inicial de espécies florestais da caatinga (Tabela 3 ).

Tabela 3 - Altura da muda em relação ao solo, relação parte aérea/raiz. comprimento de raiz da cultivar Catuaí 144 vermelho

\begin{tabular}{lccc}
\hline Tratamento & $\begin{array}{c}\text { Altura de muda } \\
(\mathrm{cm})\end{array}$ & Relação parte aérea/raiz & $\begin{array}{c}\text { Comprimento de raiz } \\
(\mathrm{cm})\end{array}$ \\
\hline Testemunha & $36,433333 \mathrm{~B}$ & $1,257778 \mathrm{~B}$ & $25,833333 \mathrm{~B}$ \\
Dose $4 \mathrm{~g} / \mathrm{ha}$ & $40,611111 \mathrm{~A}$ & $1,600000 \mathrm{~A}$ & $29,088889 \mathrm{~A}$ \\
Dose $6 \mathrm{~g} / \mathrm{ha}$ & $43,411111 \mathrm{~A}$ & $1,660000 \mathrm{~A}$ & $32,655556 \mathrm{~A}$ \\
Dose $8 \mathrm{~g} / \mathrm{ha}$ & $42,133333 \mathrm{~A}$ & $1,554444 \mathrm{~A}$ & $32,233333 \mathrm{~A}$ \\
Dose $10 \mathrm{~g} / \mathrm{ha}$ & $40,533333 \mathrm{~A}$ & $1,703333 \mathrm{~A}$ & $32,044444 \mathrm{~A}$ \\
Dose $12 \mathrm{~g} / \mathrm{ha}$ & $40,166667 \mathrm{~A}$ & $1,716667 \mathrm{~A}$ & $32,966667 \mathrm{~A}$ \\
\hline
\end{tabular}

*As médias seguidas por letras diferentes umas das outras pelo teste de Scott-Knott a 5\% de probabilidade.

$\mathrm{Na}$ avaliação dos resultados obtidos utilizando ativador de microbiota de solo $\left(\right.$ Vitasoil $^{\circledR}$ ) adquiriu-se um incremento significativo na massa seca total, massa verde total resultado esse obtido por Castro (2016), quando avaliou a influência da aplicação de filtrado de algas em parâmetros fenométricos e na produtividade da soja, obtendo como resultado aumento na massa seca total da planta de soja e altura de planta, já no parâmetro testado por Faria (2017), quando testou o desempenho de bioestimulantes e sua viabilidade econômica na cultura da soja, obtiveram resultados de forma positiva na altura de planta, comprimento de raiz e massa verde total de planta (Tabela 4).

Tabela 4 - Massa verde total e massa seca total da cultivar Catuai 144 vermelho

\begin{tabular}{lcc}
\hline Tratamentos & Massa verde total & Massa seca total \\
& g & g \\
\hline Testemunha & $42,788889 \mathrm{~B}$ & $38,32880000 \mathrm{~B}$ \\
Dose $4 \mathrm{~g} / \mathrm{ha}$ & $88,888889 \mathrm{~A}$ & $36,973333 \mathrm{~A}$ \\
Dose $6 \mathrm{~g} / \mathrm{ha}$ & $81,507778 \mathrm{~A}$ & $35,778889 \mathrm{~A}$ \\
Dose $8 \mathrm{~g} / \mathrm{ha}$ & $79,687778 \mathrm{~A}$ & $38,393333 \mathrm{~A}$ \\
Dose $10 \mathrm{~g} / \mathrm{ha}$ & $96,484444 \mathrm{~A}$ & $37,300000 \mathrm{~A}$ \\
\hline
\end{tabular}

*As médias seguidas por letras diferentes umas das outras pelo teste de Scott-Knott a 5\% de probabilidade.

Na utilização do ativador de microbiota de solo, obteve resultados positivos quando se avaliou massa seca de raiz e massa verde de raiz (Tabela 5), resultado encontrado também por Bettini (2015), a partir de aplicação de extrato de algas marinhas em cafeeiro sob deficiência hídrica e estresse salino, obteve como resultado um incremento para número de folhas, massa fresca e seca de folhas e ramos e obtendo um aumento marcante de área foliar e massa verde do sistema radicular.

$\mathrm{O}$ ativador de microbiota do solo $\left(\right.$ Vitasoil $\left.^{\circledR}\right)$ demonstrou valores significativamente superior à testemunha, nos parâmetros massa verde da parte aérea, massa seca da parte aérea (Tabela 6). Resultados semelhantes obtidos por Brant (2016), quando utilizou extrato de algas marinhas no crescimento de bananeira cv. Prata-anã na fase de aclimatação, também por Oliveira (2017), quando utilizou bioestimulantes e condicionadores de solo no cultivo de Physalis peuviana. Júnior \& Florentino (2017) destacam em seu trabalho a interação a interação positiva entre as características químicas do solo, a nutrição e produtividade do cafeeiro, onde o uso do bioestimulante proporcionou aumento nos teores foliares de boro, ferro e manganês. 
Tabela 5 - Massa verde e seca do sistema radicular da cultivar Catuai 144 vermelho

\begin{tabular}{lcc}
\hline Tratamentos & Massa verde de raiz & Massa seca de raiz \\
\hline Testemunha & $\mathrm{g}$ & $\mathrm{g}$ \\
Dose $4 \mathrm{~g} / \mathrm{ha}$ & $15,561111 \mathrm{~B}, 398889 \mathrm{~B}$ \\
Dose $6 \mathrm{~g} / \mathrm{ha}$ & $23,658889 \mathrm{~A}$ & $14,670000 \mathrm{~A}$ \\
Dose $8 \mathrm{~g} / \mathrm{ha}$ & $23,077778 \mathrm{~A}$ & $13,895556 \mathrm{~A}$ \\
Dose $10 \mathrm{~g} / \mathrm{ha}$ & $21,861111 \mathrm{~A}$ & $13,917778 \mathrm{~A}$ \\
Dose $12 \mathrm{~g} / \mathrm{ha}$ & $24,198889 \mathrm{~A}$ & $14,194444 \mathrm{~A}$ \\
\hline
\end{tabular}

*As médias seguidas por letras diferentes umas das outras pelo teste de Scott-Knott a $5 \%$ de probabilidade.

Tabela 6 - Massa verde da parte aérea e massa seca da parte aérea da cultivar Catuai 144 vermelho

\begin{tabular}{lcc}
\hline Tratamentos & $\begin{array}{c}\text { Massa verde da parte aérea } \\
\text { g }\end{array}$ & $\begin{array}{c}\text { Massa seca da parte aérea } \\
\mathrm{g}\end{array}$ \\
\hline Testemunha & $27,055556 \mathrm{~B}$ & $15,733333 \mathrm{C}$ \\
Dose $4 \mathrm{~g} / \mathrm{ha}$ & $58,174444 \mathrm{~A}$ & $30,714444 \mathrm{~A}$ \\
Dose $6 \mathrm{~g} / \mathrm{ha}$ & $54,561111 \mathrm{~A}$ & $26,946667 \mathrm{~B}$ \\
Dose $8 \mathrm{~g} / \mathrm{ha}$ & $52,621111 \mathrm{~A}$ & $27,066667 \mathrm{~B}$ \\
Dose $10 \mathrm{~g} / \mathrm{ha}$ & $56,496667 \mathrm{~A}$ & $39,987778 \mathrm{~A}$ \\
Dose $12 \mathrm{~g} / \mathrm{ha}$ & $55,008889 \mathrm{~A}$ & $35,601111 \mathrm{~A}$ \\
\hline
\end{tabular}

*As médias seguidas por letras diferentes umas das outras pelo teste de Scott-Knott a 5\% de probabilidade.

\section{CONCLUSÃO}

$\mathrm{O}$ ativador de microbiota do solo $\left(\right.$ Vitasoil $^{\circledR}$ ) aplicado via solo e foliar em mudas de café recémplantadas, promoveu um melhor desenvolvimento inicial do cafeeiro sendo observado em diâmetro, peso verde e seco, número de folhas por muda, área foliar, altura de planta, comprimento de raiz e relação parte aérea/raiz.

\section{AGRADECIMENTOS}

Os autores agradecem à Fundação de Amparo à Pesquisa do Estado de Minas Gerais (FAPEMIG / Brasil), ao Conselho Nacional de Desenvolvimento Científico e Tecnológico (CNPq / Brasil), a Coordenação de Aperfeiçoamento de Pessoal de Nível Superior (CAPES), e ao núcleo de Estudos de cafeicultura CESEP/Machado (MG).

\section{LITERATURA CITADA}

ARAÚJO, J. M. H. Algas marinhas como bioestimulantes no crescimento inicial de espécies florestais da Caatinga.
Dissertação (Mestrado em Ciências Florestais), MacaíbaRN, 2017. 47p.

AZIZ, A. et al. A laminarina desencadeia respostas de defesa na videira e induz proteção contra Botrytis cinerea e Plasmopara viticola. Molecular Plant Microbe Interaction, São Paulo, v. 16, n. 12, p. 1118-1128, 2003.

BARROS, R. S.; MAESTRI, M.; VIEIRA, M.; BRAGAFILHO, L. J. Determinação de área de folhas do café (Coffea arabica L. cv. 'Bourbon Amarelo'). Revista Ceres, Viçosa, v.20, n.107, p.44-52, 1973.

BETTINI, M. O. Aplicação de extratos de algas marinhas em cafeeiro sob deficiência hídrica e estresse salino. Tese (Doutorado em Agronomai), Botucatu-SP, 2015. 194p.

BRANT, L. A. C. Extrato de algas marinhas no crescimento de bananeira cv. Prata-Anã na fase de aclimatação. Dissertação (Mestrado em fitotecnia), Lavras-MG, 2016. $67 \mathrm{p}$.

CARDOSO, E. J. B. N. et al. Reciclagem de resíduos industriais e urbanos em solos agrícolas tropicais. Em: NIELSEN, C. J. (Ed.). Reciclagem: processos, custos e beneficios. Nova York: Nova Science, 2011. 
CASTRO, A. C. C. et al. Influência da aplicação de filtrado de algas em parâmetros fenométricos e na produtividade da soja. In: CEPE, 2016. Anais... Pirenópolis - GO, 2016. 7p.

DIAS, L. F. L. Avaliação de algumas propriedades físicas de grãos de café Coffea arabica orgânico e convencional. Dissertação (Mestrado em Agronomia). Paraná, PR: Universidade Estadual do Oeste do Paraná, 2007. 44p.

DICK, R.P. Atividades enzimáticas do solo como indicadores da qualidade do solo. Em: DORAN, J.V. et al. (Ed.) Definindo a qualidade do solo para um ambiente sustentável. Madison: SSSA; Sociedade Americana de Agricultura, 1994. p. 107-124.

DURAND, N.; BRIAND, X.; MEYER, C. O efeito de substâncias bioativas marinhas (NPRO) e citocininas exógenas sobre a atividade da nitrato redutase em Arabidopsis thaliana. Physiologia Plantarum, Malden, v. 119, n. 4, p. 489-493, 2003.

FARIA, T. C. Desempenho de bioestimulantes e sua viabilidade econômica na cultura da soja. Dissertação (Mestrado em Agronomia). Goiânia-GO, 2017. 62p.

FERREIRA, D. F. Sisvar: um guia dos seus procedimentos de comparações múltiplas Bootstrap. Ciência $e$ Agrotecnologia, v. 38, n. 2, p. 109-112, 2014

GUIMARÃES, P. T. G. et al. Cafeeiro. In: RIBEIRO, A. C.; GUIMARÃES, P. T. G.; ALVAREZ V., V. H. (Ed.). Recomendação para o uso de corretivos e fertilizantes em Minas Gerais: $5^{a}$ aproximação. Viçosa, MG: Comissão de Fertilidade do Solo do Estado de Minas Gerais, 1999. p.289-302.

JÚNIOR, K. S. F. Uso de bioativador de solo associado a diferentes coberturas vegetais e a influência nas características químicas, físicas e microbiológicas. Dissertação (Mestrado em Sistema de Produção na Agropecuária). Alfenas - MG, 2017. 74p.

KHAN, W. et al. Extratos de algas marinhas como bioestimulantes do crescimento e desenvolvimento das plantas. Journal of Plant Growth Regulation, Dordrecht, v. 28, n. 4, p. 386-399, 2009.
LIMBERGER, P. A. et al. Efeito da aplicação foliar de extrato de algas, aminoácidos e nutrientes via foliar na produtividade e qualidade de alface crespa. Revista Brasileira de Energias Renováveis, Cascavel-PR, v. 1, p. 148-161, 2012.

MATIELlo, J. B. et al. Cultura do café no Brasil, novo manual de recomendações. Rio de Janeiro; Varginha, MG: 2002. p.160-202.

MATYSIAK, K.; KACZMAREK, S.; KRAWCZYK, R. Influência de extratos de algas marinhas e mistura de ácidos húmicos e fúlvicos na germinação e crescimento de Zea mays L. Acta Scientiarum Polonorum, Lublin, v. 10, n. 1, p. 33-45, 2011.

OLIVEIRA, H. M. Bioestimulantes e condicionadores de solo no cultivo de physalis peruviana. Dissertação (Mestrado em Fitotecnia). Universidade Federal de Lavras, 2017. 40p.

RATHORE, S. S. Efeito do extrato de algas marinhas sobre o crescimento, produção e absorção de nutrientes da soja (Glycine max) sob condições de sequeiro. Revista Sul Africana de Botânica, Amsterdã, v. 75, n. 2, p. 351-355, 2009.

SCHNEIDERS, E. M. Influência do extrato de alga (Ascophyllum nodosum) sobre o desempenho da cultura da canola. Cerro Largo-RS, 2016. 56p.

SILVA, R. R. et al. Biomassa e atividade microbiana em solo sob diferentes sistemas de manejo na região fisiográfica Campos das Vertentes - MG. Revista Brasileira de Ciência do Solo, Viçosa, v. 34, p. 1585-1592, 2010.

SOUZA, R. S.; SOUZA, T. E. M. S. Caracterização das precipitações para duas regiões fisiográficas do Estado de Pernambuco. In: BIOFÍSICA 2017. Anais... Pernambuco PE, 2017. 4p.

TÓTOLA, M.R.; CHAER, G.M. Microrganismos $e$ processos microbiológicos como indicadores da qualidade dos solos. In: V. ALVAREZ, V.H. et al. (Ed.). Tópicos em ciência do solo. Viçosa: Sociedade Brasileira de Ciência do solo, 2002. v. 1, p. 487-592.

Recebido para publicação em 13/05/2019 e aprovado em 17/12/2019. 